\title{
Quantitation of RNA decay in dried blood spots during 20 years of storage
}

\author{
Fredrika Gauffin ${ }^{1}$, Ann Nordgren ${ }^{2}$, Gisela \\ Barbany $^{2}$, Britt Gustafsson ${ }^{1}$ and Håkan \\ Karlsson ${ }^{3, *}$ \\ ${ }^{1}$ Division of Pediatrics, Department of Clinical \\ Science, Intervention and Technology (CLINTEC), \\ Karolinska Institutet, Stockholm, Sweden \\ ${ }^{2}$ Division of Clinical Genetics, Department of \\ Molecular Medicine and Surgery, Karolinska \\ Institutet, Stockholm, Sweden \\ ${ }^{3}$ Department of Neuroscience, Karolinska Institutet, \\ Stockholm, Sweden
}

\begin{abstract}
Background: Diseases with an onset during childhood or adult life can have their origin during fetal life or at birth. Neonatal blood dried on filter paper (Guthrie cards) collected for screening purposes is routinely stored for decades. In addition to clinical use, these filters in combination with patient registers constitute an invaluable resource for epidemiological and pathophysiological research. Although RNA has been successfully recovered from such filters even after decades of storage, the potential decay of RNA over time has not previously been investigated using quantitative methods.

Methods: Filter papers $(n=5)$ with dried blood spots from the Swedish National PKU register, stored for 1, $5,10,15$ or 20 years were randomly selected. RNA was isolated from each sample, quantitated by spectrophotometry and reverse transcribed following DNase I treatment. Amplifiable cDNA was subsequently detected by real-time PCR using primers specific for transcripts encoding $\beta$-actin.

Results: Transcripts encoding $\beta$-actin were detected in all 25 samples analyzed at a mean threshold cycle (Ct) of 25 (SD 1.9). A one-way ANOVA indicated no significant effect of storage time on $\mathrm{Ct}$ values.

Conclusions: The lack of significant decay of RNA in dried blood filters stored for up to 20 years suggests that such filters are useful for studies of RNA determinants of diseases with an onset in childhood as well as adult life.
\end{abstract}

Clin Chem Lab Med 2009;47:1467-9.

Keywords: dried blood spots; Guthrie cards; quantitative real-time PCR; RNA.

\footnotetext{
*Corresponding author: Håkan Karlsson, Department of Neuroscience, Karolinska Institutet, Retzius väg 8 , 17177 Stockholm, Sweden

Phone: + 468524878 32, Fax: + 468325325 ,

E-mail: hakkar@ki.se

Received July 3, 2009; accepted September 1, 2009; previously published online October 28, 2009
}

\section{Introduction}

Since 1974, most newborn children in Sweden undergo screening tests for severe inborn errors of metabolism. For this purpose, four spots of whole blood are blotted on filter paper (i.e., Guthrie cards). A small amount is used for analyses and the remaining spots are stored for future clinical or research use. This procedure is routinely used worldwide.

Many diseases with an onset during childhood or adult life can have their origin during fetal life or birth. For example, fetal undernutrition, resulting in low birth weight, has been associated with increased rates of coronary heart disease, diabetes, hypertension and stroke later in life $(1,2)$. Breast cancer could have an origin due to intrauterine hormone levels (3) and in many childhood leukemias unknown events create a preleukemic clone before birth (4). Intrauterine infection can result in blindness later in life (5). Since the neonatal blood spots are collected prospectively with no selection bias and cover almost the entire population, they represent an invaluable resource for epidemiological research. Also, in combination with patient registers, they constitute a precious tool in the search for the molecular basis of a disease. However, the range of analytical possibilities is limited by the small amount of blood available. Several research groups have recovered DNA from these filter papers following long-term storage, with subsequent molecular analyses including whole genome amplification and detection of specific mutations or genetic rearrangements (6-8). In 1992, Zhang and McCabe (9) and Matsubara et al. (10) isolated RNA from dried blood spots after up to 4 years of storage. We previously reported that RNA that is suitable for PCR analyses could be retrieved from dried blood spots after 27 years of storage (11). More recently, Haak and coworkers reported that RNA amenable for quantitative gene expression analyses by both real-time PCR and microarray could be recovered from dried blood spots stored for up to 9 years (12). We investigate the impact of long-term storage on the amounts of RNA that can be retrieved from dried blood filter.

\section{Materials and methods}

Filter papers with dried blood spots from the Swedish National PKU register at the Karolinska University Hospital Huddinge, stored for 1, 5, 10, 15 and 20 years, were randomly selected. Five specimens were collected for each time point and five $3 \mathrm{~mm}$ punches of dried blood were obtained from each specimen. These neonatal dried blood spots had been stored at $4^{\circ} \mathrm{C}$ since 1981 , and in a controlled relative humidity not exceeding 30\% since 1996. 
RNA was isolated from the samples with the RNeasy Micro Kit (Qiagen, Hilden, Germany) according to the manufacturer's instructions. Briefly, filters were incubated in lysis buffer at $37^{\circ} \mathrm{C}$ for $30 \mathrm{~min}$ in a thermomixer (Eppendorf, Hamburg, Germany) at $1000 \mathrm{rpm}$. The lysates were applied to the RNeasy columns, and after careful washing, the RNA was eluted in $14 \mu \mathrm{L}$ of RNase-free water. This eluate was reapplied twice to the column to maximize yield. Eight $\mu L$ of the RNA was subjected to DNase I digestion and reverse transcribed using random hexamers as described previously (13) with reagents from Invitrogen (Carlsbad, CA, USA). Reactions prepared in the absence of reverse transcriptase were prepared in parallel to verify degradation of genomic DNA. cDNA was detected using quantitative real-time PCR (ABI 7000 SDS, Applied Biosystems, Palo Alto, CA, USA) with oligonucleotides designed to amplify fragments of the mRNAs encoding human $\beta$-actin (forward 5'-ATCCTAAAAGCCACCCCACT-3', reverse 5'-CTCAAGTTGGGGGACAAAAA-3'), as described previously (14). All samples and controls were run in triplicate (technical replicates). For the purpose of these analyses, threshold cycle (Ct) values were reported. Melting temperatures of the amplified products were obtained in a post-amplification step.

Following successful amplification, $1 \mu \mathrm{L}$ aliquots of each of the remaining eluates were applied to a Nanodrop ND1000 spectrophotometer for quantification of RNA (NanoDrop Technologies, Wilmington, DE, USA).

The study was approved by the Regional Ethics Committee, Karolinska University Hospital, Karolinska Institutet, Stockholm, Sweden.

\section{Results}

We were able to detect transcripts encoding human $\beta$-actin in all dried blood spots, regardless of storage time. Overall, such transcripts were detected at a Ctvalue of $25.1 \pm 1.9$ (mean \pm SD) in the 25 samples. All detected amplicons exhibited a uniform melting temperature. Ct values for the five biological replicates according to years of storage are shown in Figure 1. A one-way ANOVA indicated no difference between the groups $(p>0.05)$, suggesting that significant RNA decay does not occur over the 20 years period we studied. PCR reactions following CDNA synthesis in the absence of reverse transcriptase were consistently negative, indicating that the PCR products obtained during real-time PCR were templated by CDNA and confirming that DNase I treatment of the RNA efficiently eliminated contaminating genomic DNA (11). Total yield of RNA from each eluate was calculated based on spectrophotometry. Overall, $457 \pm 171 \mathrm{ng}$ of total RNA was recovered from the dried blood spots. Individual values according to years of storage are shown in Figure 2. A one-way ANOVA indicated no difference between the groups, supporting the PCR results.

\section{Discussion}

We report that transcripts encoding $\beta$-actin are readily detectable in RNA isolated from dried neonatal blood spots stored for up to 20 years. In addition, as determined using real-time PCR and spectrophotometric

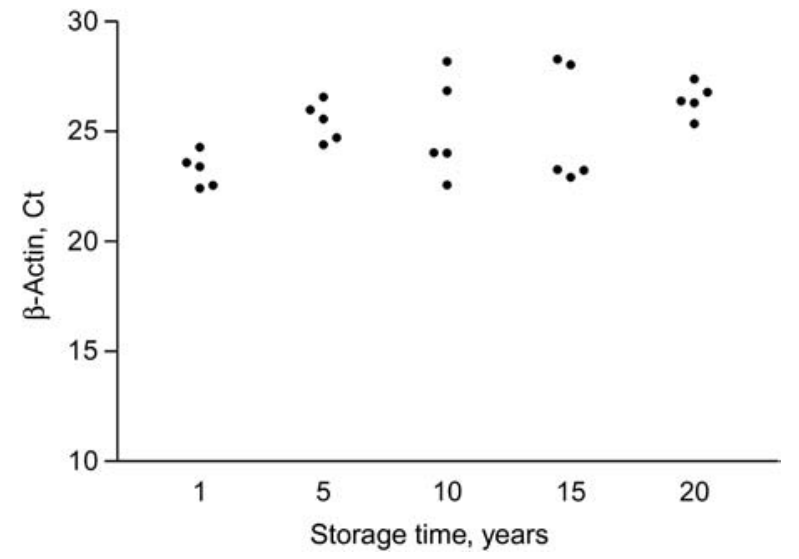

Figure $1 \mathrm{Ct}$ values obtained from an assay detecting transcripts encoding human $\beta$-actin in dried blood spots according to years of storage ( $n=5$ for each time-point).

analyses, no significant loss of transcripts appeared to occur over time. These results are consistent with a previous study, where the yield of total RNA in samples stored at ambient temperature for up to 9 years was quantified (12).

Filter papers constitute a unique resource for investigating events that may be reflected in peripheral blood cells or plasma at the time of birth and for diseases that may have an onset later in life. Even after long-term storage, previous analyses of DNA and proteins in dried blood spots have contributed to a better understanding of the pathogenesis of a number of diseases. For example, leukemia specific rearrangements found at diagnosis of children up to the age of 15 years has been detected in stored filter papers collected at birth (4). Also, antibodies and cytokines have been analyzed in dried blood spots from patients with schizophrenia or cerebral palsy after storage for more than 15 years $(15,16)$.

No studies have investigated the usefulness of RNA in dried blood filters, stored for up to 20 years, using quantitative gene expression analyses. We have shown that stored filter paper containing neonatal blood spots may be used for studies of RNA determinants of diseases with suspected origin at birth, but

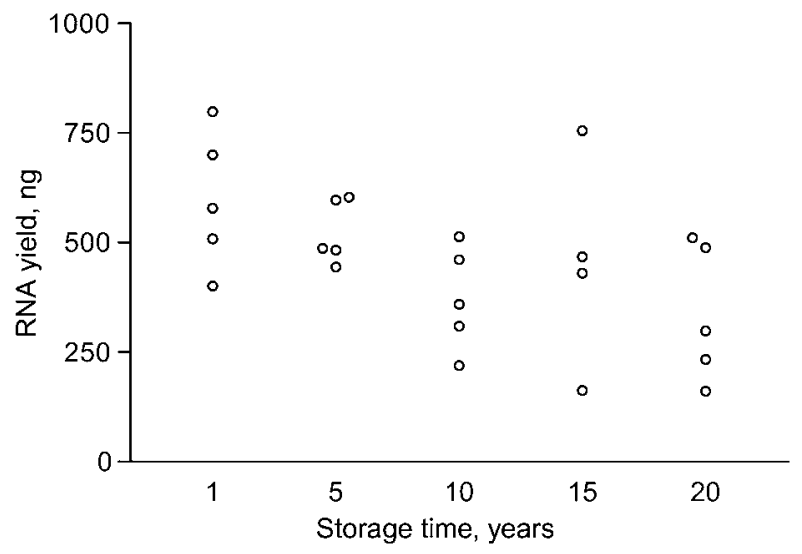

Figure 2 Yield of total RNA from dried blood spots according to years of storage as determined by spectrophotometric readings at $260 \mathrm{~nm}$. 
that may have an onset in childhood as well as adult life.

\section{Conflict of interest statement}

This work was done with no funding or support from an organization that may in any way gain or lose financially from the results. Nor have any of the authors been employed by an organization that may in any way gain or lose financially from the results. There are no other conflicting interests.

\section{Acknowledgements}

This work was supported by the Mary Bevé Foundation and the Stanley Medical Research Institute.

\section{References}

1. Barker DJ. Fetal origins of coronary heart-disease. $\mathrm{Br}$ Med J 1995;311:171-4.

2. Syddall HE, Sayer AA, Simmonds SJ, Osmond C, Cox V, Dennison EM, et al. Birth weight, infant weight gain, and cause-specific mortality - the Hertfordshire Cohort Study. Am J Epidemiol 2005;161:1074-80.

3. Baik I, Becker PS, DeVito WJ, Lagiou P, Ballen K, Quesenberry PJ, et al. Stem cells and prenatal origin of breast cancer. Cancer Cause Control 2004;15:517-30.

4. Greaves M. In utero origins of childhood leukaemia. Neonatal Update 2004 Meeting, Vol. London, England. Early Hum Dev 2005;81:123-9.

5. Mets MB, Chhabra MS. Eye manifestations of intrauterine infections and their impact on childhood blindness. Surv Ophthalmol 2008;53:95-111.
6. Sjoholm MI, Dillner J, Carlson J. Assessing quality and functionality of DNA from fresh and archival dried blood spots and recommendations for quality control guidelines. Clin Chem 2007;53:1401-7.

7. Skinner JR, Chong B, Fawkner M, Webster DR, Hegde M. Use of the newborn screening card to define cause of death in a 12-year-old diagnosed with epilepsy. J Paediatr Child H 2004;40:651-3.

8. Hjalgrim LL, Madsen HO, Melbye M, Jorgensen P, Christiansen M, Andersen MT, et al. Presence of clone-specific markers at birth in children with acute lymphoblastic leukaemia. Br J Cancer 2002;87:994-9.

9. Zhang $\mathrm{YH}, \mathrm{McC}$ abe ER. RNA analysis from newborn screening dried blood specimens. Hum Genet 1992;89: 311-4.

10. Matsubara $Y$, Ikeda H, Endo H, Narisawa K. Dried blood spot on filter-paper as a source of messenger-RNA. Nucleic Acids Res 1992;20:1998.

11. Karlsson H, Guthenberg C, von Dobeln U, Kristenssson K. Extraction of RNA from dried blood on filter papers after long-term storage. Clin Chem 2003;49:979-81.

12. Haak PT, Busik JV, Kort EJ, Tikhonenko M, Paneth N, Resau JH. Archived unfrozen neonatal blood spots are amenable to quantitative gene expression analysis. Neonatology 2009;95:210-6.

13. Asp L, Nellaker C, Karlsson H. Influenza A virus transactivates the mouse envelope gene encoding syncytin B and its regulator, glial cells missing 1 . J Neurovirol 2007:13:29-37.

14. Nellaker C, Yao YR, Jones-Brando L, Mallet F, Yolken RH, Karlsson $\mathrm{H}$. Transactivation of elements in the human endogenous retrovirus $\mathrm{W}$ family by viral infection. Retrovirology 2006;3:11.

15. Mortensen PB, Norgaard-Pedersen B, Waltoft BL, Sorensen TL, Hougaard D, Yolken RH. Early infections of toxoplasma gondii and the later development of schizophrenia. Schizophrenia Bull 2007;33:741-4.

16. Nelson KB, Dambrosia JM, Grether JK, Phillips TM. Neonatal cytokines and coagulation factors in children with cerebral palsy. Ann Neurol 1998;44:665-75. 